\title{
A propaganda multimodal como ferramenta para o ensino: a categorização inter-olfato- sensorial
}

\section{Claudir Sales de Lima}

claudir.lima@sercomtel.com.br Universidade Norte do Paraná, Londrina, Paraná, Brasil

Eliza Adriana Sheuer Nantes eliza@unopar.com.br Universidade Norte do Paraná, Londrina, Paraná, Brasil

Samira Faves Kfouri da Silva samira.kfouri@unopar.br

Universidade Norte do Paraná,

Londrina, Paraná, Brasil

\section{RESUMO}

Este artigo constitui parte integrante de uma dissertação de mestrado elaborada no Programa de Pós-Graduação em Metodologias para o Ensino de Linguagens e suas Tecnologias, da Universidade Norte do Paraná/UNOPAR. Tem como objetivo levantar o conjunto de signos que uma campanha interativa, olfativa e sensitiva traz na percepção de alunos do curso de publicidade e propaganda de uma determinada instituição de ensino superior de Arapongas/PR. Tais pressupostos nos permitiram mapear quais os signos presentes nas propagandas pesquisadas, criar um mapa de propaganda multimodal interolfato-sensorial e propor um plano de trabalho docente para os cursos de Publicidade e Propaganda. A análise das enunciações dos sujeitos, através de pesquisa descritivoanalítica e de campo, revelou a existência de diferentes percepções sobre os signos presentes na multimodalidade, vindo ao encontro das pesquisas de Rojo (2009) e Santaella (2005), e possibilitando o levantamento de novos olhares sobre o trabalho com a propaganda na sala de aula.

PALAVRAS-CHAVE: Ensino. Propaganda. Multimodal. Signos. Linguagem. 


\section{INTRODUÇÃO}

O Programa de Pós-Graduação em Ensino, Linguagens e suas Tecnologias, da Universidade do Norte do Paraná (UNOPAR), abre possibilidades para um vasto campo de pesquisas. Neste estudo específico, propomo-nos a refletir sobre como utilizar a multimodalidade na propaganda como ferramenta de ensino para os alunos do curso de Publicidade e Propaganda das instituições de ensino superior. Para Kress e Van Leewen (2001), estamos caminhando cada vez mais para a multimodalidade, com novos olhares e dentro dos princípios semióticos que nos apresentam diferentes modos de leitura de um contexto: uma música pode codificar uma ação e uma imagem, uma emoção, por exemplo.

Neste sentido, a proposta desta pesquisa visa caracterizar o gênero propaganda multimodal inter-olfato-sensorial (interativa, olfativa e sensitiva) e descrever sua contribuição para o ensino, por meio de leitura e compreensões textual, contextual, intertextual e dos vários modos de linguagens.

A proposta é representada por duas peças publicitárias. Uma das peças publicitárias está presente na revista Veja, cujo anunciante é O Boticário, e a outra, um dos Catálogos da AVON, cujo anunciante é a própria AVON. Ambas as peças publicitárias foram adaptadas para o meio Revista/Catálogo, levando a possibilidade de o leitor e/ou cliente, ou possível cliente, sentir a fragrância dos perfumes dos respectivos produtos anunciados nos próprios anúncios: um produto masculino (O Boticário) e outro feminino (AVON), este último com a atriz Luiza Brunet como destaque.

Explorar o conceito de multimodalidade mostra que, além de todas as perspectivas teóricas e as possibilidades linguísticas, audiovisuais e de imagem do discurso para as diversas disciplinas no contexto educacional, temos também de levar em consideração os valores sociais que as propagandas multimodais empregam: a riqueza de informações contidas nos mais variados formatos publicitários, independentemente das plataformas tecnológicas à disposição e da mídia utilizada.

Para conduzir o estudo, primeiramente elaboramos uma pesquisa exploratória com coleta de dados em caráter secundário. O caminho epistemológico do trabalho revela esta primeira etapa, onde conseguimos levantar informações pertinentes e aprofundar a problemática (MATTAR, 2012). Em seguida, aplicamos uma pesquisa descritivo-analítica, de campo, com questionário estruturado e perguntas abertas para levantar as diversas percepções dos respondentes em relação aos signos presentes nas peças publicitárias selecionadas para a coleta de informações pertinentes ao estudo. Segundo Marconi e Lakatos (2001), este tipo de pesquisa visa descrever quais as características de um determinado fenômeno que ocorre em uma amostra e envolve uma avaliação mais aprofundada das informações. Este estudo pode ser considerado também experimental, pois procura explicar o contexto de um evento no âmbito de um grupo. As peças foram selecionadas pelas suas diferentes características em relação aos modelos mais convencionais de comunicação publicitária.

Nesse sentido, temos como proposta desta pesquisa a confirmação através da fundamentação teórico-prático-metodológica que a vida em sociedade requer

Página | 104 
dos sujeitos apropriação dos sistemas de representação e de repertórios historicamente construídos para o aprendizado, conforme discutiremos a seguir.

\section{A PROPAGANDA, A MULTIMODALIDADE E O ENSINO}

Começamos então com um pergunta, seguida de resposta: O que é propaganda? Propaganda é qualquer forma de comunicação paga, de apresentação não pessoal e promocional de ideias, bens ou serviços e conceitos, por um anunciante patrocinador identificado. Os anúncios propagados são uma maneira lucrativa de disseminar mensagens, seja para desenvolver uma preferência de marca, seja para orientar. Já a publicidade é mídia espontânea, ou seja, gratuita (KOTLER; KELLER, 2006).

Conforme Giacomini (1991), no Estágio da Capitalismo Primitivo, há uma estimativa que no Brasil, por volta dos séculos XVIII e XIX, a economia movimentava-se por meio do negócio e das empresas pelas quais as produções aconteciam de forma artesanal, sendo o excedente direcionado para a obtenção de lucros. Primeiro, vinha a sobrevivência individual ou familiar e, depois, a obtenção de lucros. As propagandas aconteciam de forma direta, ou seja, pelo balconista, vendedor ou próprio produtor, mas ocorria, igualmente, a propaganda boca a boca, por meio da qual o consumidor ficava sabendo dos produtos e dos lançamentos, por meio de amigos, conhecidos e pequenos impressos promocionais de tiragem limitadas.

Já no Estágio da Produção em Massa, conforme Giacomini (1991), esse período é marcado pela priorização da produtividade, como o foco na maximização dos lucros, por parte dos agentes produtores e comercializadores. Todavia, a maioria das empresas brasileiras não se enquadrava nesse contexto, mas certos avanços tecnológicos do início do século XX oportunizaram o emprego na linha de produção e a comercialização massiva dos bens e serviços.

As revistas trazem uma nova forma jornalística, ou seja, valendo-se mais da mensagem visual e do texto "leve" do que páginas all type com textos maçantes. Notabilizaram-se revistas como a Revista da Semana (lançada em 1900), O Malho (1902), seguindo-se Fon-Fon, a Careta, Arara e Vida Paulistana, entre outras. As duas últimas eram publicadas em São Paulo, mantendo-se graças a anunciantes locais (GIACOMINI, 1991, p. 30, grifo do autor).

E por último, no Estágio da Sociedade Afluente, o cenário das comunicações altera-se rapidamente no país ganhando mais força ainda com a entrada das TVs. Em 1951, foi criada a TV Tupi no Rio de Janeiro; dois anos depois, é inaugurada a TV Paulista, que mais tarde faria parte da atual TV Globo, e a TV Record. Até 1962, a história da TV Brasileira só é contada por fotos e folclore, até o aparecimento do videoteipe ${ }^{1}$. Já em 1964, as Organizações Globo obtiveram a concessão do governo para definitivamente se instalar como uma emissora no Rio de Janeiro; a partir de 1968, formando um conjunto de emissoras, ficaria implantada a Rede Globo de Televisão, que dois anos mais tarde se tornaria a emissora de maior audiência do país, ampliando sua cobertura para mais de $90 \%$ de todo o território nacional até o final da década de 1980 (GIACOMINI, 1991). 
E as propagandas nos dias de hoje? Os objetivos da propaganda nos dias de hoje são reflexos das decisões anteriores sobre o mercado, o posicionamento das empresas e marcas (qual mensagem/atributo deve ser passado[a]/trabalhado[a]) e os programas de marketing. Uma meta de propaganda é uma tarefa específica de comunicação e um nível de sucesso a ser alcançado em meio a determinado público-alvo, em um flight estabelecido (KOTLER; KELLER, 2006).

A propaganda interfere sobremaneira em uma sociedade, é revestida da linguagem humana e constituída de dinamismo. No processo criativo, o pensamento humano e sua capacidade de percepção sociossensorial possibilitam a utilização (ou não) de forma privilegiada das diversas facetas linguísticas para a comunicação, de forma que possam ser tão específicos ou generalizantes quando o sentido torna-se algo situado, criado e ajustado, fruto de efeitos enunciativos, e não algo prévio, imanente e apenas identificável como o conteúdo.

Muitas atividades humanas, inclusive a propaganda, estão relacionadas ao uso da língua que se evidencia em forma de enunciados orais e escritos, dinâmicos ou não. Esses enunciados retratam práticas sociais, muitas vezes específicas, pelo seu conteúdo temático, seu "estilo" verbal (seleção de recursos lexicais, fraseológicos e gramaticais da língua), e, principalmente, sua composição organizacional (BAKTHIN, 1997).

Assim, entendemos que a formulação e a compreensão de um enunciado precisam ser vistas sob uma perspectiva interativa e contextualizada, e essa abordagem requer do pesquisador saberes e habilidades necessárias, visto que os sujeitos estão inseridos dentro de um contexto sócio-histórico altamente ideológico que reflete na produção das propagandas e estas se materializam como resultado da criatividade e inovação humana.

Esse momento dinâmico é impulsionado por mudanças sociais. Por isso, Predebon (2013) diz que, em seu cotidiano, o homem cria, recria, transforma, hibridiza saberes para suprir suas demandas interativas. Isso se faz presente quando acompanhamos as mudanças ocorridas nas diferentes gerações. Nelas, há a presença de diferentes linguagens e formas de pensar das pessoas. Influenciadas por fatores sociais, culturais, pessoais e psicológicos, propõem-se - e impõem-se - novos exercícios de criatividade no meio publicitário.

Neste sentido, observamos que as propagandas multimodais fogem dos modelos mais conservadores e convencionais, ajudando no comportamento criativo das pessoas, pois apresentam novas possibilidades de criação, leitura e releitura, por meio dos seus mais variados signos, facilitando projetos, carreiras e a vida em geral das pessoas. Entretanto, há um benefício especialíssimo para além da descoberta de novas possibilidades e soluções. Trata-se da interação da pessoa com o seu mundo: o encontro consigo mesma.

Diante do exposto, o que pode ser entendido por propaganda multimodal? Onde está ancorado esse conceito? Pela lógica, toda e qualquer linguagem é semiótica, inclusive a linguagem publicitária: sua significação busca a construção cultural e social.

A Semiótica ${ }^{2}$ considera todos os signos e as diversas formas de apresentação e manifestação desses signos, de forma linguística ou não. A propaganda multimodal está inserida em um contexto de multiformas, multilinguagens, multimídias, multissignos, multissentidos. Conforme Marcuschi (2007), o sentido 
pode ser considerado um fenômeno socialmente produzido e quando não existe a interação, não há sentido algum. $\mathrm{O}$ autor complementa ainda que, nas suas mais diversas formas de manifestação, o contexto é inalienável, interativo para produção de sentido. Dessa forma, podemos dizer, então, que a propaganda multimodal é altamente interativa.

Para Santaella (2007, p.29), a Semiótica tem como função classificar e descrever todos os tipos de signos possíveis de forma lógica. Isso poderia caracterizá-la como de maior relevância sobre as outras ciências, uma vez serem todas constituídas de linguagens, signos a serem estudados na busca de uma razão. A partir da Fenomenologia, podemos "ler o mundo como linguagem" (SANTAELLA, 2007, p. 30). A Fenomenologia peirciana considera como fenômeno tudo aquilo que a nossa mente percebe, não fazendo quaisquer julgamentos de falsos ou verdadeiros: engloba tudo aquilo que percebemos, também não julga se são fatos reais ou ilusórios, certos ou errados. Assim, seriam para Peirce ${ }^{3}$ a descrição e a análise das experiências que acontecem em nosso dia a dia:

\footnotetext{
Entendendo-se por fenômeno qualquer coisa que esteja de algum modo e em qualquer sentido presente à mente, isto é, qualquer coisa que apareça, seja ela externa (uma batia na porta, um raio de luz, um cheiro de jasmim), seja interna ou visceral (uma dor no estômago, uma lembrança ou reminiscência, uma expectativa ou desejo), quer pertença a um sonho, ou uma ideia geral e abstrata da ciência, a fenomenologia seria, segundo Peirce, a descrição e análise das experiências que estão em aberto para todo homem, cada dia e hora, em cada canto e esquina de nosso cotidiano (SANTAELLA, 2007, p. 32).
}

Na visão de Rojo (2009), existem vários gêneros discursivos que exigem leitores aptos a entender as mais variadas formas de construção expressiva, os sentidos propositalmente formados. Os textos multimodais incorporam as modalidades de linguagem verbal (oral e escrita) e não verbal, e podem ser chamados de textos multissemióticos.

Rojo (2009, p. 107) complementa que a multissemiótica ou a multimodalidade de linguagens explora um conjunto de signos/linguagens "exigidos pelos textos contemporâneos, ampliando a noção de letramentos para o campo da imagem, da música, das outras semioses que não somente a escrita".

Por isso, as discussões que envolvem o processo de ensino-aprendizagem devem ser um constante objeto de reflexão na prática docente, principalmente, porque estão em jogo diversas formas de conhecimento e leituras por parte dos educandos. Muito importante também é os alunos estarem de fato aprendendo com os novos modelos adotados pelos professores a partir de uma profunda reflexão da prática docente, assevera Marinho (2007).

Para Moran (2007), na nova sociedade, a tecnologia permite que a informação e o conhecimento veiculem-se de uma forma muito rápida, modificando sobremaneira as organizações sociais. Várias plataformas como notebooks, celulares, palmtops, entre outros, permitem que todos fiquem constantemente conectados, acessando e trocando informações diversas. Espera-se que as cidades estejam cada vez mais conectadas, tornando-se, aos poucos, grandes centros digitais, cidades inteligentes, e os serviços, o lazer e a aprendizagem virtualizem-se com este movimento. 
A sociedade da informação faz que os professores repensem a forma de ensinar e a comunidade a repensar o saber, impactando, consideravelmente, na educação do país. O aprender vive uma grande transformação, segundo Andersen (2015), com reconfigurações do conhecimento, provocadas pela função mediadora, praticamente universal, das novas tecnologias e que facilitam as complexas aprendizagens.

Andersen (2015) complementa que a sociedade da informação precisa converter-se em uma sociedade da descoberta. Necessita de um raciocínio inclinado e projetos multidisciplinares que buscam informações e conhecimento. Por isso, a utilização de recursos tecnológicos pode ser uma alternativa propícia para o ensino. $O$ crescimento e a evolução dos programas (softwares) são aliados para a guarda de uma grande quantidade de dados: mídias estáticas (textos, fotografias, gráficos) e mídias dinâmicas (vídeos, áudios, animação), promovendo esses recursos em grande escala, movimentando a educação para a realidade de hoje.

Pensando especificamente na propaganda como ferramenta de ensino, concordamos que muita coisa mudou, em alinhamento com as ponderações de Cabral (2001, p. 122):

\begin{abstract}
A publicidade era ainda um jogo em que se ganhavam e perdiam fortunas dos outros, especulando-se sobre o poder de persuasão da mensagem. Então, como uma das principais consequências desse fenômeno, a intuição, que servira de base na troca de mercadorias e produtos por milhares de anos, foi finalmente substituída pelo conhecimento científico e pela experimentação de novas e poderosas técnicas de vendas e estímulos de consumo (CABRAL, 2001, p. 122).
\end{abstract}

Conforme Andersen (2015), as mudanças nos aspectos comportamentais, psicológicos e cognitivos já podem ser observadas em um ser humano cada vez mais integrado com os projetos de pesquisa, que impactam uma sociedade necessitada de estudos sobre os vários temas disponíveis. A propaganda não pode ser ignorada, precisa fazer parte desse contexto, nos bancos das instituições de ensino superior, sobretudo, nos cursos de Publicidade e Propaganda.

Para Coll e Monereo (2010), o papel do professor enquanto educador não deve ser simplesmente transmitir informação, mas de selecionar e gerir os diversos recursos disponíveis na educação, por meio dos quais o aluno deverá administrar a sua aprendizagem e conviver harmoniosamente com as tecnologias relacionadas. De qualquer forma, não podemos negar as contribuições históricas e práticas pedagógicas que os modelos até então utilizados sugerem, por exemplo, as aulas expositivas.

Após o embasamento teórico acima, foi possível realizarmos a pesquisa de campo, cujo objetivo foi estabelecer um vínculo com a aplicabilidade daquele saber junto ao ensino. Para isso, aplicamos uma pesquisa descritiva e analítica, com a coleta de dados primários junto aos alunos de Publicidade e Propaganda de uma Instituição de Ensino Superior na cidade de Arapongas-PR. Mattar (2012) afirma que dados primários não foram antes coletados e são pesquisados com o objetivo de atender às necessidades específicas da pesquisa em andamento. 
Segundo Gil (2008, p. 28), a pesquisa descritiva descreve as características de determinadas populações ou fenômenos.

Algumas pesquisas descritivas vão além da simples identificação da existência de relações entre variáveis, pretendendo determinar a natureza dessa relação. Neste caso, tem-se uma pesquisa descritiva que se aproxima da explicativa.

Os resultados desta pesquisa reportamos a seguir.

\section{REFLEXÕES SOBRE OS RESULTADOS DA PESQUISA EM CAMPO}

Nesta seção apresentamos as peças publicitárias que motivaram a pesquisa e o aprimoramento dos conceitos de propaganda multimodal e também os resultados obtidos com a pesquisa descritivo-analítica de campo, confirmando o quadro epistemológico deste estudo. Depois de fazer um diagnóstico com os alunos para descobrir qual o nível de conhecimento sobre propaganda e os referenciais de propaganda multimodal, percebemos que os alunos respondentes, até então, só haviam tido contato com as propagandas convencionais (sem os conceitos da multimodalidade). Neste sentido e na sequência, foi apresentada uma proposta de nivelamento sobre as propagandas multimodais, alinhando-os com os referidos conceitos, já expostos anteriormente com base nos diversos autores citados até aqui, para então entrarmos nesta etapa que aborda especificamente a multimodalidade, através da apresentação das peças publicitárias selecionadas e questionário estruturado com questões abertas, como veremos a seguir.

A propaganda, representada por duas peças publicitárias, foi categorizada pelos autores deste projeto como propaganda inter-olfato-sensorial, após a análise dos dados coletados com os respondentes. Uma das peças publicitárias está presente na revista Veja, cujo anunciante é O Boticário e a outra, no catálogo da Avon, e o anunciante é a própria Avon. Ambas as peças publicitárias foram adaptadas para o meio revista/catálogo, levando a possibilidade de o leitor e/ou cliente, ou possível cliente, sentir a fragrância dos perfumes dos respectivos produtos anunciados nos próprios anúncios: um produto masculino (O Boticário) e outro produto feminino (Avon), este último com Luiza Brunet como garota propaganda, conforme as imagens a seguir:

Figura 1 - Propaganda O Boticário

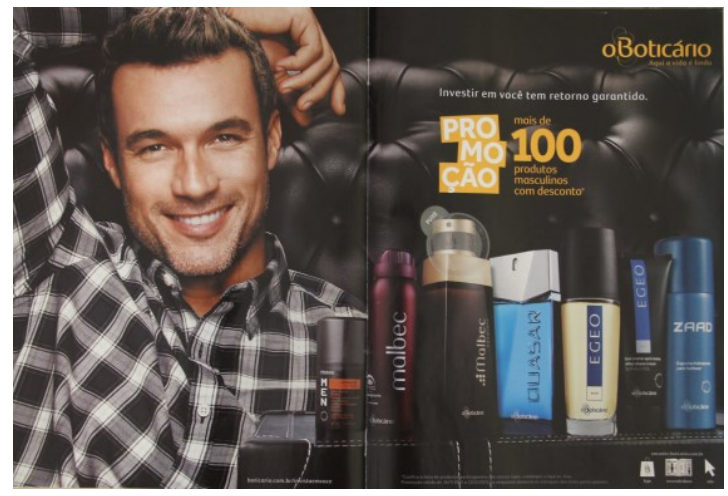




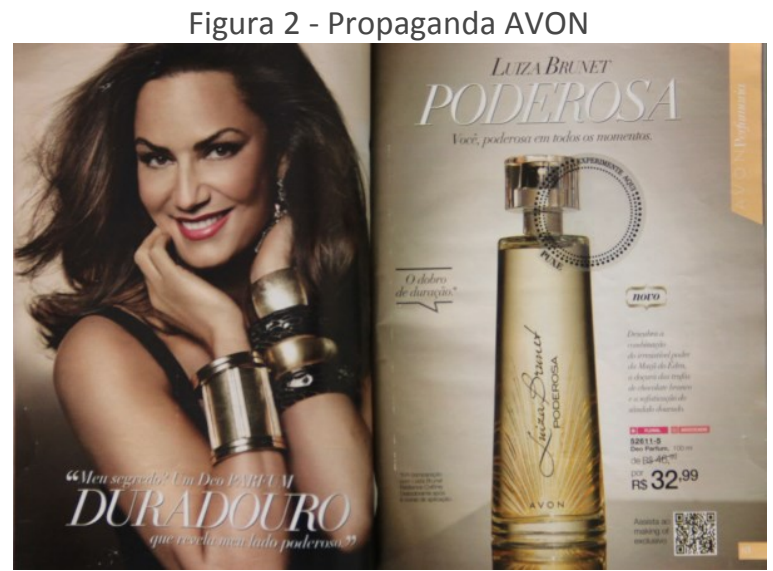

Fonte: Catálogo Avon (2015)

Apresentamos um resumo da campanha da Avon: Avon Lança Deo Perfum Luiza Brunet Poderosa. Primeiro Deo Parfum de Luiza chega para complementar a marca Luiza Brunet, uma das marcas TOP 10 da Avon no Brasil.

Parceira da Avon há mais de 10 anos, Luiza Brunet é uma das celebridades mais queridas do consumidor brasileiro. Prova disso é que as fragrâncias Luiza Brunet e Luiza Brunet Radiance são sucesso de vendas no folheto da empresa, e colocam a marca Luiza Brunet entre as fragrâncias mais vendidas da Avon no país.

Luiza Brunet Poderosa, que chega ao mercado em janeiro, é o primeiro Deo Parfum de Luiza Brunet. Traz um exclusivo Acorde Absoluto, versão que combina ingredientes, como frutais suculentos, florais absolutos, cremosidade aditiva e madeiras nobres, agregando caráter, assinatura, intensidade e duração ao perfume.

Na saída estão presentes notas frescas de maçã do éden, pêra e grapefruit natural, que realçam o brilho e a exuberância de Luiza. As trufas de chocolate branco unem-se à magnólia francesa - flor real e imperial, símbolo de elegância - e ao muguet, em um corpo de buquê floral aveludado e intenso, realçando sua feminilidade e a elegância. As notas de fundo trazem a combinação de cacau e musk ao sândalo dourado australiano, madeira cremosa e envolvente, que garante um magnetismo duradouro, tornando a fragrância intensa e cativante.

A imagens das referidas peças publicitárias, vistas anteriormente, foram apresentadas aos alunos respondentes e solicitado aos mesmos que respondessem as questões a seguir, onde trazemos já os dados coletados e as reflexões sobre os resultados desta pesquisa.

\section{a) Qual sua opinião justificada sobre estas propagandas?}

O gráfico a seguir ilustra um conjunto de variáveis, que mostram as diferentes leituras apresentadas e oportunizadas pelos respondentes após serem tabuladas/cruzadas para uma melhor compreensão acerca dos resultados obtidos. 
Gráfico 1 - Opinião justificada sobre a propaganda

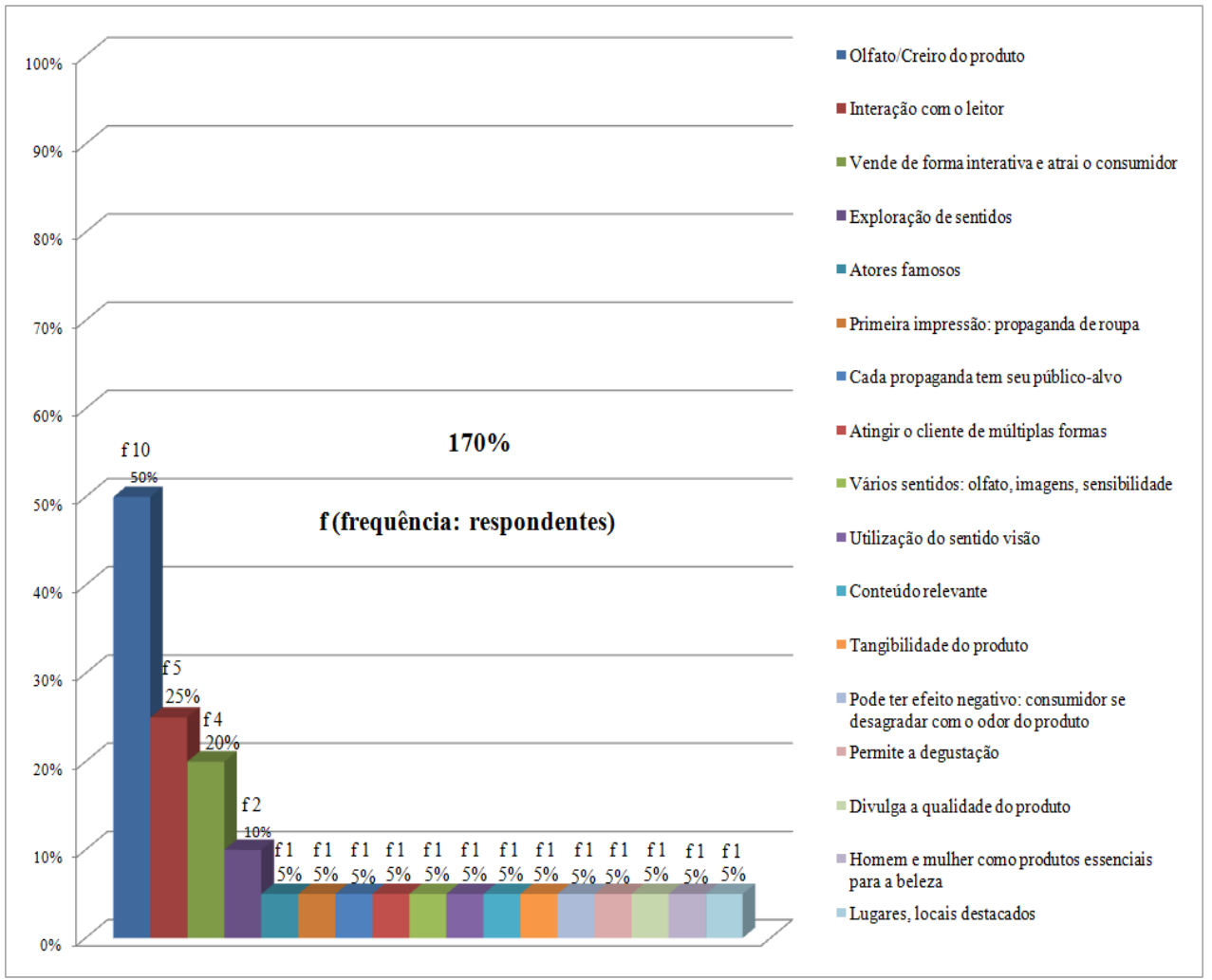

Fonte: os próprios autores (2016)

Nas enunciações dos sujeitos, percebemos no gráfico que metade dos respondentes (50\%) tem como opinião o sentido olfato como forma justificada da propaganda analisada: a) "É interessante, pois permite que o cliente sinta levemente o cheiro do produto antes de comprá-lo. Mas tem um ponto negativo, pois o cheiro pode ser prejudicado no processo e, no final, pode ser desvalorizado."; b) Minha opinião é que as duas propagandas chamam a atenção pelos atores que são famosos e por você poder sentir o cheiro."; c) "Estas propagandas levam o leitor a interagir com a revista, tanto pelo olfato quanto visual."; outros (25\%) justificaram as peças como propaganda interativa: a)" Um patamar acima dos demais da revista. Motivo? A interação do leitor/consumidor é levada a outro nível [...]"; b) "Propaganda que tem a interação do leitor [...]"; c) "Ganha pontos de atenção pela interatividade e 'degustação' além de marcas com o leitor sobre a qualidade do produto"; Outros (20\%) disseram que vende de forma interativa e atrai o consumidor; (10\%) afirmam ter a exploração dos sentidos, (5\%) reconhecem a presença de atores famosos; (5\%) disseram que a primeira impressão está alicerçada na propaganda de roupa; $(5 \%)$ julgaram que cada propaganda tem seu público-alvo; (5\%) consideram que as peças atingem os clientes de múltiplas formas; (5\%) admitem vários sentidos nas peças: olfato, imagem e sensibilidade; (5\%) qualificam a utilização do sentido visão; (5\%) acreditam ter um conteúdo relevante; (5\%) reconhecem a tangibilidade do produto; $(5 \%)$ pensam ter efeito negativo: o consumidor pode desagradar-se com o odor do produto; (5\%) consideram que as revistas permitem a degustação; $(5 \%)$ reputam a divulgação da qualidade do produto; (5\%) qualificam o homem e a

Página | 111 
mulher como produtos essenciais para a beleza; por fim, (5\%) qualificam os lugares, locais destacados nas peças publicitárias.

As enunciações dos respondentes deixam evidente tratar-se de uma propaganda que utiliza recursos sensoriais relacionados ao olfato/cheiro. Segundo Santaella (2005, p. 74), "O olfato capta energia química numa troca de partículas que chegam pelo ar. No paladar, esta troca de partículas se dá no próprio corpo. Quanto mais a percepção sensória fica rente ao corpo, menos podemos pensar com aquele sentido".

Desse modo, o recurso utilizado na propaganda em questão traz uma percepção maior e correlação com o produto/marca. A interação e o apelo para as vendas são recursos reconhecidos pelos sujeitos, e confirmados por Sissors e Bumba (2001, p. 16): "a interatividade de publicidade e mídia pode resultar em melhores vendas".

Os dados indicam que o olfato/cheiro, a interação com o leitor e os apelos às vendas de forma interativa, atraindo o consumidor, são fortes indícios de ferramentas sensoriais e multimodais para chamar a atenção em uma peça publicitária. Uma campanha publicitária convencional e chamada de "clichê" pelos publicitários em geral já não chama mais a atenção, é apenas mais uma entre tantas outras. Os dados indicam também um despertar dos alunos (respondentes) para o tema da multimodalidade em questão, comprovado pelas respostas que chegaram a um percentual de 170 e as várias possibilidades elencadas por eles.

Os dados revelam ainda uma forte exploração dos sentidos, que está se tornando uma prática, por parte da indústria da comunicação, em adotar estratégias baseadas na exploração dos sentidos do consumidor/cliente, a fim de conseguir a sua atenção e persuadi-lo na compra das marcas anunciadas. Vários estímulos sensoriais foram percebidos pelos alunos: não somente o olfato, a interação e apelos de vendas. Arnheim (1992) confirma que a percepção é um forte meio para realizar a descrição de certos fenômenos. Para o autor, é a representação mental de objetos ou acontecimentos exteriores, alinhada com o centro nervoso, com base em uma ou múltiplas impressões sensoriais, em uma integração em um conjunto de percepções, condutas e atos correlatos.

b) Identifique e avalie o conjunto de signos utilizados nesta propaganda (linguagem verbal, não verbal e outros recursos)

A seguir, o gráfico traz enunciações relacionadas ao conjunto de signos utilizados na propaganda em questão, com uma rica exposição das possibilidades que uma propaganda multimodal pode proporcionar. O cruzamento dos dados aconteceu de forma a padronizar as respostas para uma melhor compreensão: 
Gráfico 2 - Conjunto de signos percebidos

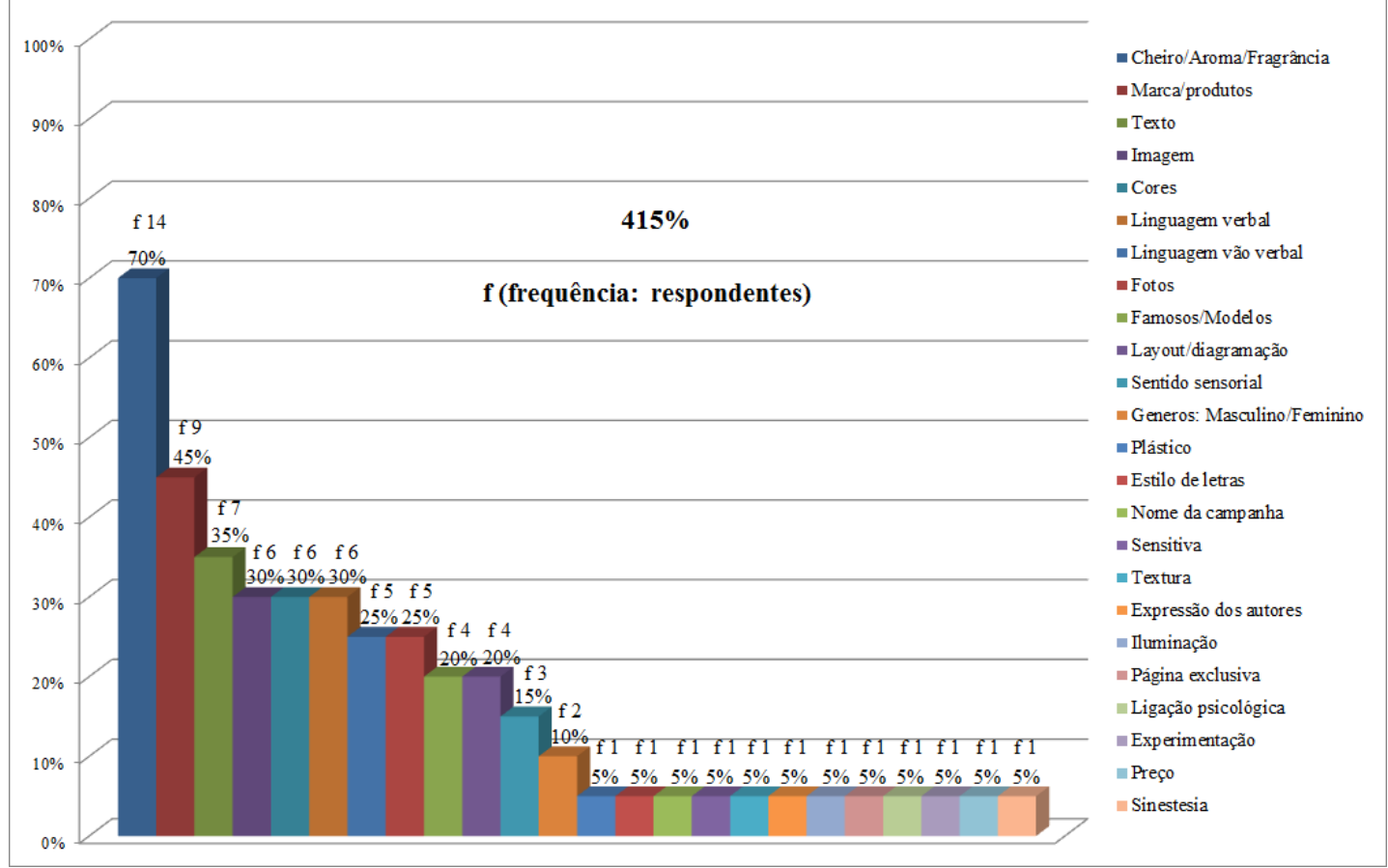

Fonte: os próprios autores (2016)

Os dados mostram que a grande maioria (70\%) identifica e avalia o cheiro/aroma/fragrância como o principal signo para a peça publicitária em questão. Outro dado importante levantado pelos respondentes $(45 \%)$ foi a marca, seguido de texto (35\%). Os respondentes (30\%) detectaram também que a imagem é um importante signo presente na peça publicitária, seguido de cores (30\%) e linguagem verbal (30\%). Classificaram (25\%) como linguagem não verbal e apontaram (25\%) para fotos. Os respondentes $(20 \%)$ constataram a presença de famosos/modelos na peça e observaram (20\%) o layout/diagramação como fator importante na composição da propaganda; (15\%) dos entrevistados consideram ser uma propaganda sensorial e (10\%), voltada para os gêneros masculino e feminino; outros (5\%) revelaram a presença de plástico na composição da peça publicitária; (5\%), o estilo das letras; $(5 \%)$ apontaram o nome da campanha; (5\%) disseram ser uma campanha sensitiva; (5\%) constataram a textura como um signo importante; (5\%) perceberam a expressão dos atores; (5\%) mencionaram a iluminação na produção da peça; (5\%) afirmam ser uma página exclusiva; (5\%) classificam a ligação psicológica que a propaganda possui com o leitor; (5\%) acharam interessante a proposta de degustação do produto; (5\%) classificaram o preço como importante; e (5\%) revelam a sinestesia na peça publicitária.

Muitas são as variáveis e possibilidades apresentadas pelos respondentes, mas fica evidente que cheiro/aroma/fragrância está no centro da percepção dos sujeitos nessa peça publicitária, muito alinhado a uma determinada marca/produto. Tatit (1997) diz que o olfato é o sentido da aspiração do perfume afetivo envolvido no contato passional, e o verbo sentir que se estende da sensação olfativa vai até a percepção geral das qualidades sensíveis do mundo. Textos, imagens, cores e a linguagem verbal, como um todo, são muito perceptíveis também aos olhos dos respondentes, assim como as fotos, a presença de famosos, layout/diagramação da revista/peça publicitária. Outros 
signos não deixam de ser importantes para a composição da peça publicitária, conforme as enunciações.

Os dados indicam que há um forte apelo do anunciante para com o leitor, utilizando recursos visuais e sensitivos para prender a atenção e apresentar o produto, por meio da experimentação: o cheiro do produto. Segundo Calazans (2006, p. 157), "em geral, a ideia de dispor de um cheiro é estimular o bem-estar do cliente no lugar e, consequentemente, aumentar a predisposição à compra".

Percebemos também uma forte evidência da Semiótica, a qual, na conceituação de Dionísio (2011), traz a multimodalidade à tona, referindo-se às mais distintas formas de representação utilizadas na construção linguística de uma dada mensagem, que pode ser através de uma peça publicitária, tais como: palavras, imagens cores, formatos, marcas/traços tipográficos, disposição da grafia, gestos, padrões de entonação, olhares, etc. Esclarece Moura (2011) que outros elementos, não relacionados somente ao texto, podem ser vistos, tais como: artes visuais, fotografia, publicidade de produto, vestuário, elementos diversos, atores, textura, iluminação, gestos, cultura, etc.

c) Qual o principal recurso explorado nesta propaganda e que garante a interatividade do o leitor (cliente) com o material (peça publicitária)?

As proferições proporcionaram a formatação do gráfico a seguir, que mostra os resultados destacados pelos respondentes. Executamos a análise dos dados, unificando as respostas por grupos e procedendo à tabulação com respostas:

Gráfico 3 - Principal recurso explorado na propaganda

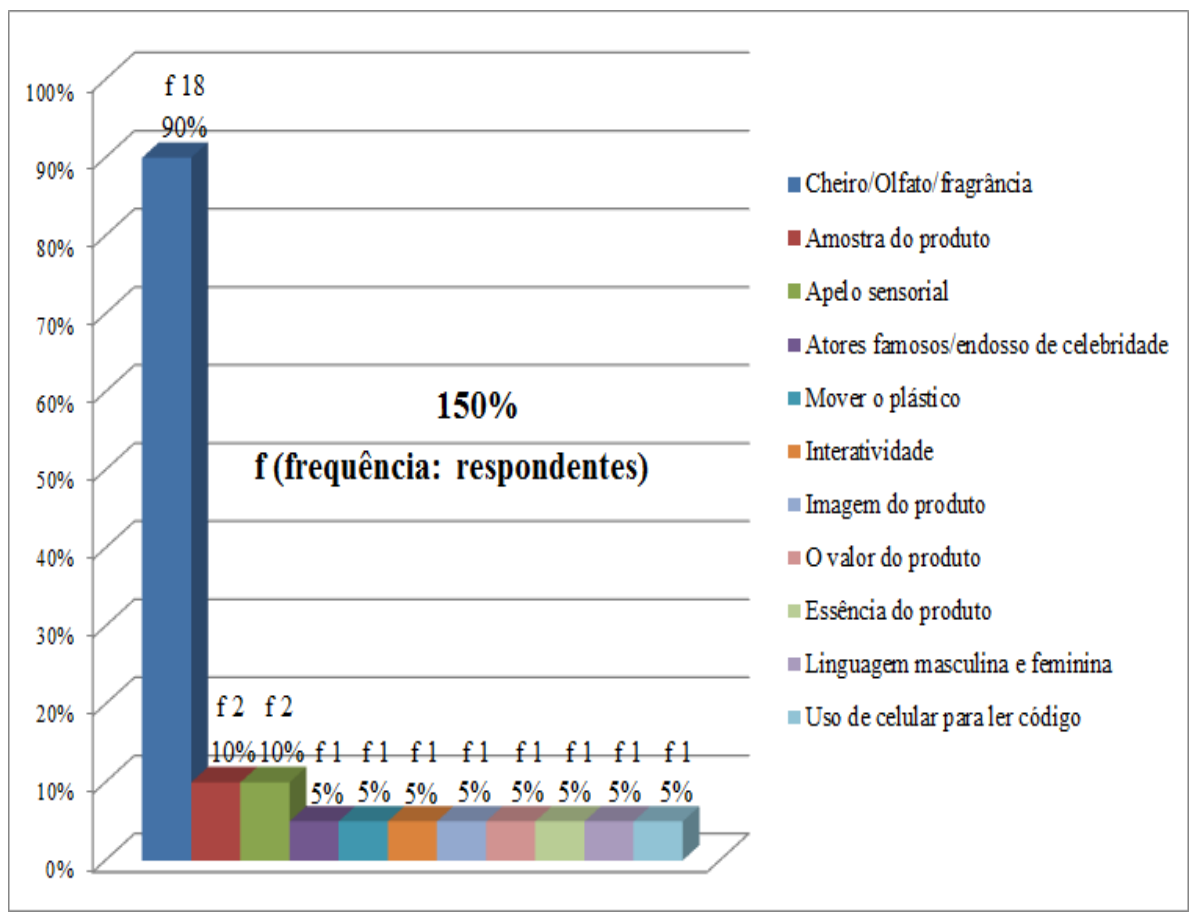

Fonte: os próprios autores (2016)

Quando questionado aos pesquisados qual o principal recurso explorado na peça publicitária (propaganda) que garantia a interatividade com o leitor (cliente), quase a totalidade (90\%) apontou o cheiro/olfato/fragrância como a principal recurso: a) "A possibilidade de sentir o cheiro."; b) "Os atores por serem 
famosos e o cheiro que você pode sentir na hora."; c) "Demonstração da fragrância sem a necessidade de tê-lo em mãos."; d) "O olfato do leitor, como estímulo de trazer no anúncio a possibilidade do contato com o cheiro do produto". Apenas (10\%) dos entrevistados apontaram a amostra do produto como um signo importante; outros $(10 \%)$ reconheceram o apelo sensorial com fator importante; $(5 \%)$ detectaram a presença de atores famosos e o endosso à campanha e/ou produto enquanto celebridade; (5\%) citaram o mover de um plástico que cobre a fragrância inserida na peça publicitária; (5\%) apontaram a interatividade com um ponto importante a ser observado nessa categoria de propaganda; (5\%) mencionaram o valor do produto; $(5 \%)$ falaram da essência do produto (pode ser entendido como características); (5\%) revelaram o apelo de linguagem para os públicos masculino e feminino; por último, outros (5\%) apontaram a necessidade do uso de celular para ler o código presente na revista (pin code).

Notamos, nas enunciações dos sujeitos, que o principal recurso explorado na propaganda em questão é o cheiro/olfato/fragrância, citado quase na sua totalidade, ou seja, (90\%) dos respondentes. De acordo com conceitos do marketing sensorial, revelados por Rocha (2005), é preciso criar uma sinergia sensorial com os atributos buscados. E complementa que os aspectos culturais, simbólicos, presentes nas embalagens, rótulos, propagandas, slogans e anúncios em geral influenciam na percepção dos clientes. Assim, fica evidente que os elementos citados, de natureza verbal ou não verbal, além do principal, são imprescindíveis para a comunicação materializar-se de forma plena.

Os dados indicam riqueza de detalhes e signos categorizados, desde o emprego de recursos sensoriais até a interação, por meio de plataformas tecnológicas (celulares). Segundo Kress (2009), analisando do ponto de vista da Semiótica, podemos dizer que modos semióticos referem-se a sistemas de recursos semióticos, os quais tornam a comunicação possível. Para Kress (2009 p. 54), "modo é um recurso social e culturalmente moldado para construção de significado. Imagens, escrita, layout, música, gestos, discurso, movimento, trilha sonora são exemplos de modos usados na representação e comunicação". Rocha (2005) corrobora para chegarmos à conclusão de a linguagem humana poder ser entendida, de forma ampla, como uma herança social e cultural, que nos permite (re)elaborar uma ampla quantidade de conceitos e fundamentos, e a possibilidade de contínua pluralização e desenvolvimento cognitivo.

Os dados apontam ainda haver percursos cognitivos plausíveis, que elucidam a construção da peça publicitária em questão e do raciocínio que depreende para a compreensão, em consonância com a análise semiótica, a qual, centrada na olfato/cheiro, não se restringe à identificação de outros símbolos como signos comunicativos. Os dados indicam também que a peça publicitária é altamente dependente do contexto, na perspectiva de haver muitos intervenientes para restabelecer, adequadamente, por meio de processos inferenciais, a intenção pretendida pelo anunciante.

Então, mediante os estudos até aqui, e por meio dos dados levantados nessa abordagem sobre as referidas propagandas multimodais, elaboramos um mapa para a categoria em questão, no qual podemos ver os mais diversos signos apontados pelos alunos, e o denominamos: mapa da multimodalidade interolfato-sensorial. 


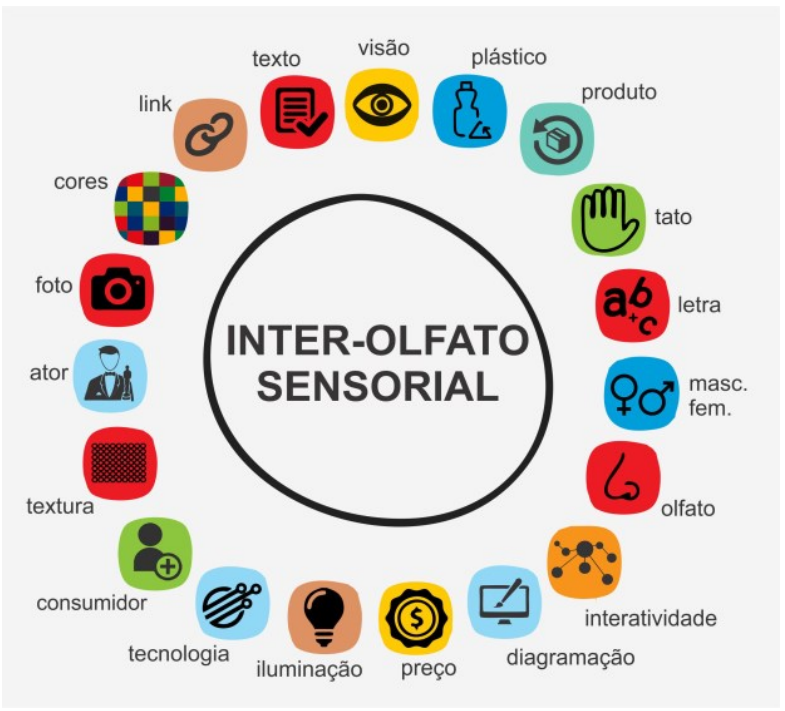

Fonte: os próprios autores (2016)

Além do levantamento de informações para o aprimoramento e novas respostas ao estudo sobre a multimodalidade nas propagandas, um dos objetivos deste estudo é também sugerir trabalhos em sala de aula com propagandas multimodais, para desenvolver o aprendizado de conteúdos diversos, a partir da constituição desses materiais. A seguir, apresentamos a contribuição para essa modalidade de propaganda multimodal: inter-olfato-sensorial. Trata-se de um plano de trabalho docente para os alunos dos cursos de Publicidade e Propaganda, em instituições de ensino superior.

Quadro 1: Plano de trabalho docente para o curso de Publicidade e Propaganda

PLANO DE TRABALHO DOCENTE: PROPAGANDA MULTIMODAL: INTER-OLFATO-SENSORIAL Instituição de Ensino: UNIVERSIDADE Curso: 70 Semestre A Período: Noturno

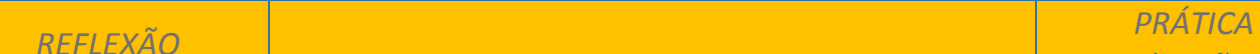

REFLEXÃO

Contextualização

da propaganda

TEORIA

multimodal na

categoria

Interatividade por

meio Sensorial

Prática social inicial

do conteúdo

através da reflexão

Objetivos:

- Reconhecero

gênero

"propaganda

multimodal" em

suas dimensões:

contexto criativo e

de produção,
Construção teórica das práticas que levam à multimodalidade da propaganda através de Interatividade por Meio Sensorial.
As aplicações dos conceitos através de práticas em sala de aula, laboratórios e pesquisa.

\begin{tabular}{c|c|c|c}
$\begin{array}{c}\text { Problemat } \\
\text { ização do } \\
\text { conteúdo }\end{array}$ & Instrumentalização & Catarse & $\begin{array}{c}\text { Aplicações práticas } \\
\text { do conteúdo }\end{array}$ \\
$\begin{array}{c}\text { Discussão } \\
\text { sobre o }\end{array}$ & Ações docentese & Síntese mental & Intenções do aluno: \\
conteúdo: & - Apresentação: & - Apropriação & (i) Conhecer mais \\
- Por que & conhecimento dos & dos conteúdos & modalidade de \\
estudar & alunos sobre a & disponíveis na & propaganda: a \\
propagan & propaganda & propaganda & "propaganda \\
da & multimodal na & multimodal de & multimodal". \\
multimod & categoria & forma & (ii) Valorizaro
\end{tabular}




\begin{tabular}{|c|c|c|c|c|}
\hline 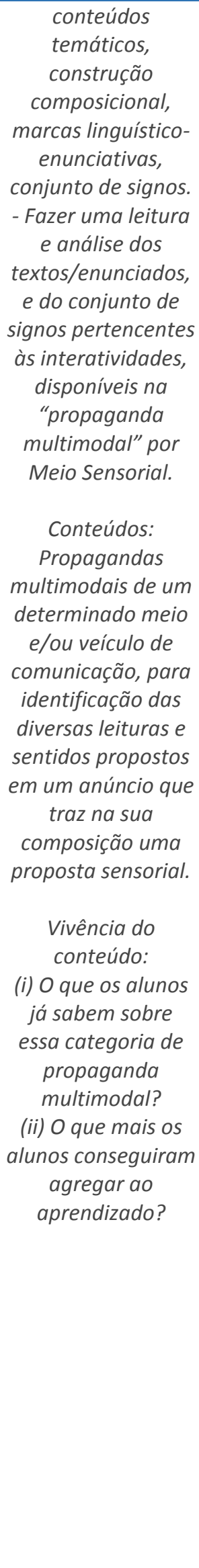 & 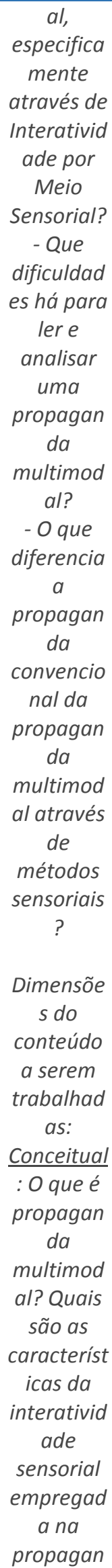 & $\begin{array}{c}\text { interatividade por } \\
\text { meio sensorial; } \\
\text { - Exposição } \\
\text { dialogada do } \\
\text { conteúdo pelo } \\
\text { professor na } \\
\text { categoria interativa } \\
\text { por meio sensorial. } \\
\text { - Atividades de } \\
\text { leitura e sentidos } \\
\text { das questões } \\
\text { referentes às } \\
\text { possibilidades da } \\
\text { propaganda } \\
\text { multimodal } \\
\text { (contexto de } \\
\text { produção; conteúdo } \\
\text { temático; } \\
\text { construção } \\
\text { composicional; } \\
\text { marcas linguístico- } \\
\text { enunciativas; e } \\
\text { conjunto de signos). } \\
\text { Recursos: } \\
\text { Humanos e } \\
\text { materiais } \\
\text { (livros; textos } \\
\text { diversos; meios de } \\
\text { comunicação e as } \\
\text { respectivas peças } \\
\text { publicitárias } \\
\text { multimodais: } \\
\text { datashowe } \\
\text { internet). }\end{array}$ & $\begin{array}{c}\text { categorizada: } \\
\text { meios } \\
\text { sensoriais. } \\
\text { Expressão da } \\
\text { síntese: } \\
\text { - Debate sobre } \\
\text { o assunto } \\
\text { (temas). } \\
\text { - Atividades } \\
\text { para que o } \\
\text { aluno } \\
\text { demonstre sua } \\
\text { compreensão } \\
\text { sobre a } \\
\text { propaganda } \\
\text { multimodal e } \\
\text { suas } \\
\text { categorias. } \\
\text { - Atividades de } \\
\text { leitura e } \\
\text { análise de } \\
\text { propagandas } \\
\text { multimodais: } \\
\text { comparação } \\
\text { entre as } \\
\text { propagandas } \\
\text { selecionadas } \\
\text { em diferentes } \\
\text { suportes. }\end{array}$ & $\begin{array}{l}\text { saber crítico- } \\
\text { reflexivo. } \\
\text { (iii) Aprender a ler e } \\
\text { apreciar } \\
\text { textos/enunciados } \\
\text { e conjunto de } \\
\text { signos da } \\
\text { propaganda } \\
\text { multimodal a ser } \\
\text { estudada. } \\
\text { (iv) Valorizar o } \\
\text { conhecimento } \\
\text { através de novas } \\
\text { leituras. } \\
\text { Ações do aluno: } \\
\text { (i) Leitura de outros } \\
\text { anúncios de } \\
\text { propaganda } \\
\text { multimodal por } \\
\text { Meio Sensorial e de } \\
\text { outros } \\
\text { suportes/plataform } \\
\text { as; } \\
\text { (ii) Pesquisar, na } \\
\text { mídia impressa e } \\
\text { eletrônica, peças } \\
\text { publicitárias sobre } \\
\text { multimodais por } \\
\text { (iv) Organizar a } \\
\text { socialização desse } \\
\text { saber. } \\
\text { para discussão em } \\
\text { sala de aula. } \\
\text { (iii) Compartilhar } \\
\text { com outros alunos } \\
\text { o entendimento e o } \\
\text { aprendizado. }\end{array}$ \\
\hline
\end{tabular}




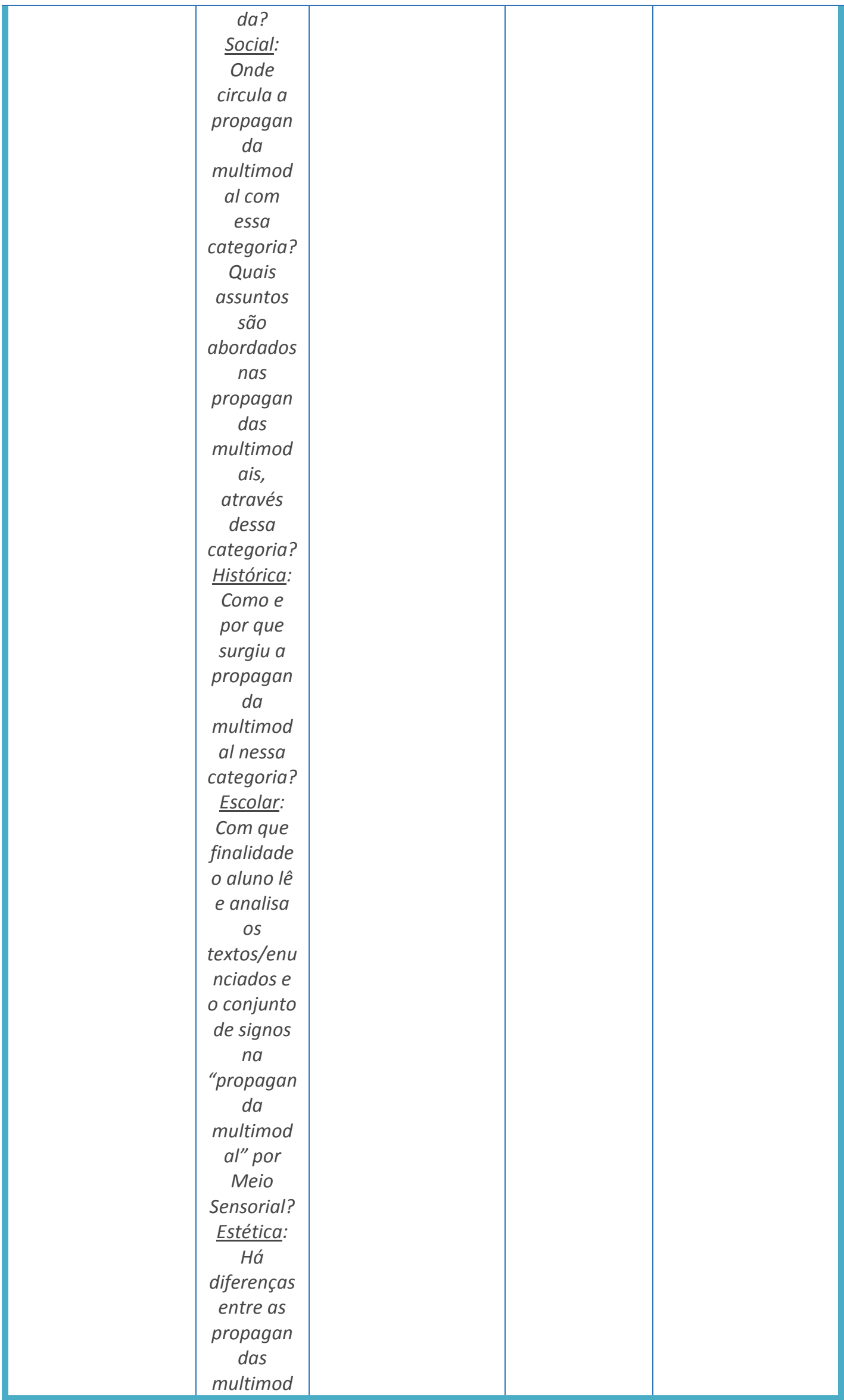




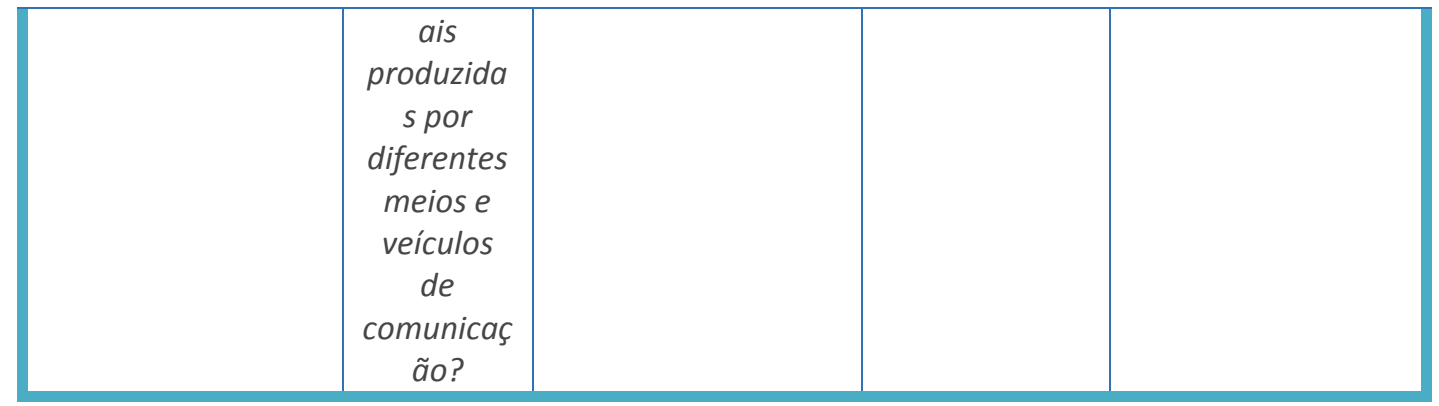

Fonte: Adaptação do quadro de Gasparin (2007) e do Plano de Trabalho Docente

(LUNARDELLI, 2012, p. 222).

\section{CONSIDERAÇÕES FINAIS}

Com base nas reflexões deste estudo, concluímos que, após todas as proposições elencadas, são muitos os percursos cognitivos para elucidar a construção das peças publicitárias e provocar o raciocínio lógico. Este depende da compreensão dos alunos, em consonância com a análise semiótica que, centrada nos signos levantados, não se restringe à identificação de outros símbolos como signos comunicativos. Os dados também apontaram que as peças publicitárias são altamente dependentes do contexto, na perspectiva de haver muitos intervenientes para restabelecer adequadamente, por meio de processos inferenciais, a intenção pretendida pelo anunciante.

Para finalizar, propomos a formulação de novas práticas de ensino, por meio das propagandas multimodais, que não permaneçam às margens do curso de Publicidade e Propaganda, mas sejam levadas para outros cursos e tragam novos olhares, pesquisas e discussões no âmbito acadêmico. 


\title{
Multimodal advertising as a tool for teaching: the inter-sense-sensory categorization
}

\begin{abstract}
This study is part of a master's dissertation elaborated in the Undergraduate Program in Methodologies for Teaching Languages and their Technologies, from the University of Paraná / UNOPAR. It aims to raise the set of signs that an interactive campaign, olfactory and sensitive brings in the perception of students of the course of advertising and Publicity of an institution of higher education in Arapongas / PR. Such assumptions allowed us to map which signs were present in the advertisements researched, to create a map of multimodal advertising with an eye-sensory and to propose a teaching work plan for the courses of Advertising and Publicity. The analysis of the subject's enunciations expressed the existance of different perceptions about the signs exposed on this multimodality, in agreement with the researches of Rojo (2009) and Santaella (2005), what enables new perspectives about the role of advertising in classrooms.
\end{abstract}

KEYWORDS: Teaching. Advertising. Multimodal. Signs. Languages. 


\section{NOTAS}

${ }^{1}$ Conhecido também como VT. Processo eletrônico de registro de imagens de televisão numa fita de matéria plástica recoberta de partículas magnéticas. Disponível em:<https://www.dicio.com.br/videoteipe/>. Acesso em: 12 nov. 2016.

${ }^{2}$ Segundo Nöth (2003), a palavra semiótica tem sua origem na expressão grega semeîon, que quer dizer "signo", e "sêma", traduzido por "sinal" ou "signo".

${ }^{3}$ Charles Sanders Peirce era físico e astrônomo. Dentro das Ciências Culturais, estudou particularmente Linguística, Filosofia e História, com contribuições também na área da Psicologia Experimental. Estudou praticamente todos os tipos de ciência em sua época, sendo também conhecedor de mais de dez idiomas.

${ }^{4}$ Pin code é um código numérico de identificação pessoal: PIN - Personal Identification Number. Disponível em:<http://brainly.com.br/>. Acesso em: 21 jun. 2016.

\section{REFERÊNCIAS}

ANDERSEN, E. (Org). Linguagens, leituras, mídias e ensino. São Paulo: Cia do Ebook, 2015.

ARNHEIN, R. Arte e percepção visual: uma psicologia da visão criadora. Tradução de Ivonne Terezinha de Faria. 7. ed. São Paulo: Nova Versão, 1992.

BAKHTIN, M. M. Estética da Criação Verbal. Tradução de Maria Emsantina Galvão G. Pereira. 2. ed. São Paulo: Fontes, 1997.

CABRAL, A. O Jogo no Ensino. Lisboa: Notícias Editorial, 2001.

CALAZANS, F. M. A. Propaganda Subliminar Multimídia. São Paulo: Summus Editoria, 2006.

DIONISIO, A. P. Gêneros Multimodais e Multiletramento. In: KARWOSKI, A. M. GAYDCZKA, B.; BRITO, K. S. (Orgs). Gêneros Textuais: reflexões e ensino. Rio de Janeiro: Lucerna, 2005.

COLL, C.; MONEREO, C. Educação e Aprendizagem no Século XXI: Novas ferramentas, novos cenários, novas finalidades. In: COLL, C.; MONEREO, C. (Orgs.). Psicologia da Educação Virtual: Aprender e ensinar com as tecnologias da informação e comunicação. Porto Alegre: Artmed, 2010. p. 15-46. 
GASPARIN, J. L. Uma didática para a Pedagogia Histórico-Crítica. 4. ed. Campinas: Autores Associados, 2007.

GIACOMINI FILHO, G. Consumidor Versus Propaganda. São Paulo: Summus, 1991.

GIL, A. C. Como elaborar projetos de pesquisa. 4. ed. São Paulo: Atlas, 2008.

KRESS, G.; VAN LEEUWEN, T. Reading images. The grammar of visual design. Londres; Nova York: Routledge, 1996.

KRESS, G. What is mode? In: JEWITT, C. (Org.). The Routledge Handbook of Multimodal Analysis. London: Routledge, 2009.

KOTLER, P.; KELLER, K. L. Administração de marketing. 12. ed. São Paulo: Pearson Prentice Hall, 2006.

LUNARDELLI, M. G. Um haicai para o estágio, um estágio para o haicai: diálogos sobre o gênero discursivo e a formação docente inicial. Londrina, PR: Biblioteca Digital UEL, 2012.

MARCONI, M. A.; LAKATOS, E. M. Metodologia do trabalho científico. 6. ed. São Paulo, SP: Atlas, 2001.

MARCUSCHI, L. A. Da fala para a escrita: atividades de retextualização. 8. ed. São Paulo, SP: Cortez, 2007.

MARINHO, H. R. B. et al. Pedagogia do Movimento: universo lúdico e psicomotricidade. 2. ed. Curitiba, PR: Ibpex, 2007.

MATTAR, F. N. Pesquisa de marketing. São Paulo, SP: Atlas, 2012.

MORAN, J. M. et al. Novas Tecnologias e mediação pedagógica. Campinas, SP: Papirus, 2007.

MOURA, J. S. A. Elementos de Semiótica. Maceió, AL: IFAL, 2011.

PREDEBON, J. Criatividade: abrindo o lado inovador da mente. 8. ed. São Paulo, SP: Pearson, 2013.

Página | 122 
ROCHA, E. Totetismo e mercado: notas para uma antropologia do consumo. In: ENCONTRO ANUAL DA ASSOCIAÇÃO NACIONAL DE PROGRAMAS DE PÓSGRADUAÇÃO EM ADMINISTRAÇÃO, 24., 2005. Anais... [S. I.]: ENANPAD, 2005.

ROJO, R. Letramentos múltiplos, escola e inclusão social. São Paulo, SP: Parábola Editorial, 2009.

SANTAELLA, L. Matrizes da linguagem e pensamento: sonora visual verbal: aplicações na hipermídia. 3 ed. São Paulo, SP: Iluminuras, 2005.

SANTAELLA, L. Semiótica aplicada. 3. ed. São Paulo, SP: Pioneira Thomson Learning, 2007.

SISSORS, J. Z.; BUMBA, L. Planejamento de mídia. Tradução de Karin Wright. São Paulo, SP: Nobel, 2001.

TATIT, L. Musicando a semiótica: ensaios. São Paulo, SP: Annablume, 1997.

Recebido: 05 jul. 2017.

Aprovado: 30 ago. 2017.

DOI: http://dx.doi.org/10.3895/etr.v1n1.6087.

Como citar:

LIMA, C. S.; NANTES, E. A. S.; SILVA, S. F. K. A propaganda multimodal como ferramenta para o ensino: a categorização inter-olfato-sensorial. Ens. Tecnol. R., Londrina, v. 1, n. 1, p. 103-123, jan./jun. 2017. Disponível em: <https://periodicos.utfpr.edu.br/rbqv/article/view/6087>. Acesso em: XXX.

Correspondência:

Claudir Sales de Lima

Rua Porto Alegre, 713, Apto 103, Jardim Agari, Londrina, Paraná, Brasil.

Direito autoral:

Este artigo está licenciado sob os termos da Licença Creative Commons-Atribuição 4.0 Internacional.

(c) (1) 